REMOVAL OF A SCIRRHOUS TUMOUR OF THE BREAST: INHALATION OF ETHER. By W. M. Trousdare, Esq., West Butterwick.

Mrs. Barnard, of West Ferry, aged 62, of bilious temperament, mother of two children, first perceived a small turnour on the lower part of the right breast about two years ago. Lately it had increased much in size, and become painful. It presented all the characters of scirrhus, being hard, circumscribed, and moveable. The skin covering its surface was slightly adherent and puckered, but the nipple not retracted, nor the glands in the axilla affected. On Iay 8 th, $I$ operated for its removal, in the presence of Mr. Robert Eminson, of Scotter, and my assistants. The vapour of æther was previously administered from Bell's apparatus. The patient inhaled it seven minutes, when she became perfectly insensible. The excision of the tumour was then effected in about three minutes, by two elliptical incisions, of seren inches in length, including the nipple, and a greater portion of the breast, and two small arteries required to be tied.

During the operation the patient talked deliriously, and appeared quite unconscious of what was being done. On her return to consciousness, which took place in ten minutes, she was asked whether she had felt any pain, and replied, "Not the least : I know nothing about it." Whilst inhaling the æther, her pulse rose from 75 to 110 , but soon after subsided to 90. She complained of headache and considerable stiffness of the nuscles for a few days, but had no other unfurourable symptoms.

\section{2ospital Reports.}

\section{LIVERPOOL NURTHERN HOSPITAL.}

A report of the medical cases treated at the Northern Hospital, daring the yoar terminating 31st December. 1846, was lately read to the Liverpool Medical Society, by Dr. Ternball, one of the physicians to the hospital. The following is an abstract of the paper:-

At present the hospital contains 104 beds, but it can accommodate 180 patients, when the completion of the docks at the north end of the town will render increased accommodation necessary. The institution was originally intended chiefly for the reception of accidents, and acute or urgent medicul cases; and though it has, since the new building was opened, assumed more the character of a general bospital, the medical, as well as the surgical cases, are still chiefly of the same severe description. The severity of the casee arises from the hospital being situated near to the most densely populated and nuhealthy part of the town, und from being also close to the docks and shipping. From the latter it receired many bad cases of scurry, dysentery, pulmonary consumption, and various organic diseases, which, from their nature, or from not being attended to at sea, are peculiarly severe and fatal.

During the year 1846, the number of medical cases admitted was 731; of surgical, 889 ;-that is, 1620 patients treated in the hospital. To these must be added 94 remaining from the preceding year, and 789 outpatients, (chiefy slight accidents,) making in all 2503.

Of the 731 medical cases, there were 59 classed as febrile diseases ; 29 of these were cases of intermittent fever in seamen, most of them from the United States, and from the coast of Africa. In this class there was but one fatal case.

Of rheumatic affections there were 149 cases, three of which were fatal.

Of diseases of the nerrous system there were 66 cases, and fire of them fatal; three died from apoplexy, one from hemiplegia, and one from intoxication with rum.

Of diseases of the respiratory organs, there were 152 cases, 29 of which proved fatal. Of the latter, 17 were cases of pulmonary consumption.

Of diseases of the organs of circulation and of the blood, there were 30 cases, and eight of them proved fatal. There was one death from purpura hæmorrhagica, two from scurvy, and five from disease of the heart.

Of diseases of the stomach and intestinal canal, there were 155 cases; and of these, 20 were fatal. There were 105 cases of diurrhcea and dysentery, 16 of which died.

Of diseases of the liver, there were 21 cases, two of which were fatal.

Of dropsy, there were 33 cases, six of which died.

Of diseases of the urinary organs, there were five casas; of uterine diseases, ten; of secondary syphilis and skin diseases, 39 ; of diseases of the eye, four; and eight cases of other diseases not classified, including one fatal case of inflammation of the air passages from the fumes of nitrous acid.

The rale of mortality in 1846 was higher than usnal. The total number of cases treated in the hospital, excluding those remaining from the preceding year, and out-patients, was 1620, and the deaths, 135, or one in 12; 731 were medical cases, of which 74 died, or one in $9 \frac{7}{\mathrm{~s}}$. From comparing this with a table for the year 1843, I find that the mortality was above the average, 42 deaths having occurred in that year in 507 medical cases, or one in 124. That the mortality should have been higher than usual, does not, however, seem surprising, when we find, from the reports of the Registrar General, that it was much above the arerage over the whole kingdom, (50,000 in England and Wales above the average in 1846 ,) chiefly owing to the prevalence of diarrbca and dysentery. In the Northern Hospital these diseases proved fatal in sixteen cases, thus standing next to pulmonary consumption, which was the cause of death in seventeer.

It should, however, be observed, that a higher rate of mortality wight at all times be looked for in this hospital than in most others, owing to the ordinary state of health of the population from which it receives many of its inmates, and the severe nature of the cases. The annual mortality of the whole population of Liverpool is about one in 28; so that it would seem that the deaths amoug the medical cases during their period of sickness in the hospital was three times greater than among the whole population annually. The recent extensive emigration from Ireland, which 